\title{
Fish Transcriptomics: Applied to our Understanding of Aquaculture
}

Joseph Heras

Department of Integrative Biology and Museum of Vertebrate Zoology, University of California, Berkeley. 3101 Valley Life Sciences Building, University of California, Berkeley. Berkeley, CA 94720-3160.

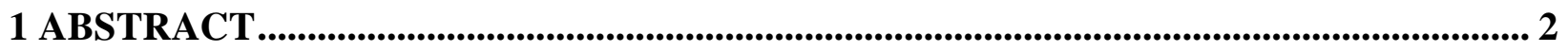

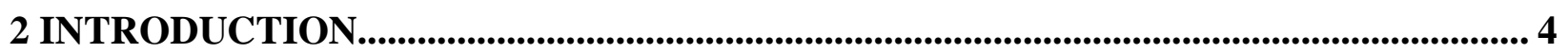

3 NUTRITION, GROWTH AND DEVELOPMENT ......................................................... 9

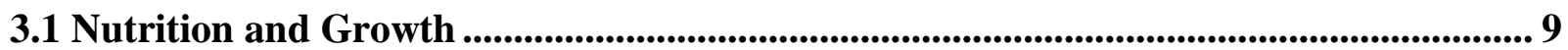

4 REPRODUCTION AND DEVELOPMENT ................................................................. 14

5 IMMUNE FUNCTION, STRESS, AND TOXICOLOGY ............................................ 16

6 ADAPTATIONS, MOLECULAR EVOLUTION, AND POPULATION GENETICS..... 18 7 MICROBIOME AND APPLICATIONS FOR CONSERVATION AND AQUACULTURE MANAGEMENT ............................................................................. 20

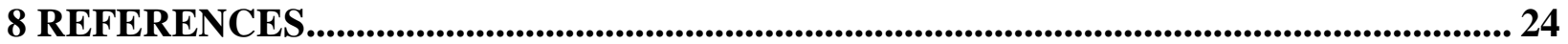




\section{ABSTRACT}

New challenges arise in the face of global climate change which impact every ecosystem on earth, including aquatic systems. This is evident in observations made in regard to the world's oceans, which show trends of incremental changes in ocean surface temperatures, sea levels, and ocean acidity. These environmental shifts impact human resources such as fisheries and aquaculture. In addition, according to the World Bank, the increase in human population will also require more food and nutrient production, which include industries such as aquaculture. With this increasing demand in aquaculture and fisheries, we must develop efficient and productive methods to operate these industries. We can use genetic methods, specifically transcriptomic information to better understand the biology of our source of nutrition. With the advent of RNASeq techniques, we can provide a better understanding about growth and development, immune function and stress, and adaptations. The use of population genetics or (genomics) to detect Single Nucleotide Polymorphisms (SNPs) between populations or closely related species can provide greater insight from stock structure to fishery-induced evolution. In addition, candidate loci can be investigated further to better understanding evolutionary processes, which provide clues on physiological adaptations and gene expression patterns that can help elucidate how these organisms respond to their current environment. In addition, the use of transcriptomic analyses such as differential gene expression can be used to determine resilience in various environmental conditions such as pollution, hypoxic/anoxic conditions, fluctuations in salinity, and temperature extremes. There has been an increase in transcriptomic studies for many aquaculture species, which has aimed at improving our understanding of growth, development, and metabolism, providing vital information for fisheries and aquaculture industries to make adjustments to 
environmental conditions such as oxygen availability, nutrition, and salinity. All of these aspects provide insightful information for advancing our knowledge of aquaculture, fisheries and conservation management. 


\section{INTRODUCTION}

As the demand for aquaculture increases, the use of innovative methods to improve the health and quality of these industries are crucial. By 2050, the human population will likely reach 9 billion, which will require more food and nutrient production, which will include aquaculture industries (Barange et al. 2018; World Bank, 2013). With this increasing demand in aquaculture and fisheries, we must develop efficient and productive methods to operate these industries. In addition, there are a vast amount of changes to environmental conditions due to climate change and with a finite amount of resources available, this poses challenges for improving aquaculture production (Barange et al. 2018). With the advancement in genetic sequencing technologies (i.e. next-generation sequencing, NGS) and computational methods, we can use genomic and transcriptomic information to better understand the biology of our source of nutrition (production of aquaculture) and improve production. Also, advancements in technology and bioinformatic tools have bolstered many "omic" fields which include transcriptomics but also genomics, metabolomics, proteomics and metagenomics (Chandhini and Kumar, 2019). All "omic" fields including transcriptomics provide extensive amounts of data and the opportunity to understand aquaculture from a holistic approach and address the issues associated with growth, nutrition, disease, and conservation. Aquaculture practices are global efforts, which have an economic impact and provide food resources throughout the world. Here lies many aspects of what is gained from sequencing transcriptomes from aquatic organisms that are targeted for food and nutrition.

With the advent of RNA-Seq techniques, we can provide a better understanding about biological systems in which many studies have generated data for aquaculture purposes and have made strides and efforts on a better understanding of nutrition, growth, reproduction, immune 
function and stress, and adaptations for species used in aquaculture industries (Escalante-Rojas et al 2018; Leduc et al. 2018; Yang et al. 2018; table 1). Although many species may have similar biochemical and physiological properties, life histories, diet, and physiological adaptations, these features can be unique to an array of species. RNA-Seq techniques are a powerful tool which have multiple applications and can be applied to many facets of biology. Therefore, RNA-Seq techniques offer a unique perspective on gene expression which can be applied to better understand the physiology, behavior, evolution, endocrinology, ecology, population genetics, and conservation of the species of interests used in aquaculture. We can use these novel genetic methods to make stronger efforts in aquaculture production and conservation, in which optimal production can be available, and with a stronger understanding about the biology of these aquaculture species, we can strive toward stronger sustainable practices.

Transcriptomics allows us to identify transcripts (RNA molecules) from a given cell or tissue type from an organism (Wang et al. 2009). Most transcriptomic studies have focused on messenger RNA (mRNA) molecules, because these molecules demonstrate that a gene is expressed, and the mRNA molecule will be translated into a protein product which serves a function within the cell or tissue. With high-throughput sequencing technologies, such as NGS, these sequencing technologies can be used for genomic and transcriptomic applications. Transcriptomic analyses would not be possible without the use of methods such as RNA-Seq technologies (Wang et al. 2009) and advancement in computation power and programming. With a population of RNA, whether it's total RNA or targeted with poly(A)+, these molecules are transformed into a library of cDNA fragments (Wang et al. 2009). With these libraries, nextgeneration sequencing (i.e. Illumina, Oxford Nanopore, and Pacific Biosciences) can be implemented to generate a vast amount of sequence reads. In the past, transcriptomes were 
quantified with either sequence or hybridization on custom made microarrays (Clark et al. 2002, Reinartz et al. 2002), but this required prior knowledge of genomic sequences, and were timeconsuming and highly laborious (Chandhini and Kumar, 2018). With current methods, prior genomic information is not required to sequence a transcriptome of a given organism. Once the transcriptome has been produced from one of the various sequencing platforms, multiple analyses can be conducted and give insight on the cellular processes for any species of interest and investigate questions associated with changes in diet, environment, or exposure to a pathogen. Analyses include transcriptome annotation, SNP detection, differential gene expression, gene enrichment, detection of alternative splice variants, identification of orthologous sequences, and estimation of positive Darwinian selection. It is evident and there are abundant studies applying RNA-Seq techniques to aquaculture aimed at improving the health and quality of the desired species of interest (Chandhini and Kumar, 2018).

Also, the use of transcriptomic information has been a cost-efficient tool to utilize, especially in the absence of a genome for the species of interests. However, with the constant reduction in sequencing costs, genomes can be readily available and used as a complement to transcriptomic analyses. In the past couple of years, there has been extensive amount of research to develop fast and reliable software needed for genomic sequencing on "single node" computers which contain multi-threaded processors (Martinez et al. 2018). The transcriptome can be used in a wide range of applications such as identifying a collection of protein encoding genes, the composition of a gene with alternative splicing and post translation modifications, and lastly measure differential expression of hundreds to thousands of genes within a given individual (Chandhini and Kumar, 2019). Transcriptomic studies allow us to better understand gene expression within a temporal framework, where we can ask questions about how gene expression 
changes during different time periods. This insight on any changes in gene expression profiles can better explain which genes are involved in growth, diet shifts, metabolism, and development. This temporal aspect used in transcriptomic analyses could not be identified solely with the use of genomic sequencing. Genomic sequencing only provides the location of genes within chromosomal arrangements but does not provide insight on how these genes are expressed within a given tissue or time point. Many studies investigate which genes are up-regulated or downregulated during developmental stages, which is crucial in understanding growth. With improved insight on growth and reproduction, many industries seek to produce quick growth rates and simultaneously reduce the amount of stress and diseases present during production. Gene expression patterns provide a unique opportunity to better understand how organisms respond to altered environmental conditions such as co-occurrence of hypoxia and high pCO2 (Cline et al. 2020) or exposure to pollutants (Pojolar et al. 2012). Also, transcriptomic analyses can have a spatial context (e.g. targeting a specific tissue type or whole organism). These questions can provide answers about genes which encode for proteins within a given tissue that are essential for a physiological function such as digestion, reproduction, and/or adaptations.

As more genomic resources become available for more species important for aquaculture purposes, many studies have focused on the use of model species such as zebrafish (Danio rerio), Japanese rice fish (Oryzias latipes) and Japanese pufferfish (Fugu rubripes), which sequenced genomes have been used to make inferences about growth, development, fish physiology, diet, metabolism, immune function and response to toxins (Ulloa et al. 2014; Mazurais et al. 2011). With the genome at hand, transcriptomes have been generated for these model species where many bioinformatic pipelines pave the methodology for studies on non-model organisms. Many studies have shown multiple genes that are up-regulated and down-regulated in which multiple 
experimental designs can be developed to understand a variety of aspects of an organism such as metabolism of certain nutrients, disease and stress pathways, and development of specific organs, and the results of these studies can be applied to aquaculture (Dahm and Geiser, 2006). As more transcriptomic and genomic studies are developed, more patterns can be elucidated where we can delineate whether there are clear patterns that transcend multiple species or can be restricted to a few species because of unique evolutionary adaptations.

Currently, a vast amount of transcriptomic and genomic sequence data is being generated for multiple organisms, where the data extensively exceeds the amount of analyses completed (Schadt et al. 2010). With this immense amount of sequence data available, this requires us to adopt the use of advanced computational resources (Schadt et al. 2010). With the vast amount of data deposited on major sequence databases [DNA Data Bank of Japan - DDBJ (Japan), GenBank (USA) and European Nucleotide Archive (Europe)], this information can be used for many comparative genomic and transcriptomic analyses. In addition, within the past 20 years sequencing data costs have decreased dramatically, where the cost per megabase (Mb or 1,000,000 base pairs) of sequence data is a couple of U.S. cents (Wadapurkar and Vyas, 2018). With these current reductions in costs of genetic sequencing gives rise for efforts to obtain sequencing information for the species of interests, but also analysis of closely related species which can give a broader understanding about the ecological and evolutionary relationships which can be crucial for conservation and aquaculture management. Aquaculture genetics had begun around 80 years ago and has steadily grown in the past thirty years (Dunham and Lucas, 2019). Advancements in genetics and breeding research has been established for commercial species such as carps, catfish, salmonids, tilapias, and oysters; all of which have been genetically improved (Dunam and Lucas, 2019). However, we do not see a widespread of genetic studies on aquaculture species, where 
some reports show that only $10 \%$ of commercial aquaculture species are genetically improved (Gjedrem et al. 2012; Gjedrem and Robinson et al. 2014).

With this vast amount of genetic information, the following type of questions can be addressed. What type of immune response occurs in the presence of a pathogen? Which genes are expressed when the composition of a diet has been changed (i.e. less fish meal)? How does this novel diet or lack of nutrients impact immune function, growth and reproduction? How has this vast amount of information improved our management for conservation and fisheries? New methods will be crucial for developing demand of the aquaculture in the upcoming years. Here I provide a review of why transcriptomics would will be vital to our understanding of fisheries and aquaculture.

\section{NUTRITION, GROWTH AND DEVELOPMENT}

\subsection{Nutrition and Growth}

One of the most crucial objectives in aquaculture is selecting nutrient resources optimal for aquaculture. However, what are impacts of these diets on these species such as growth, digestion, metabolism, immune function, and reproduction? Of course, many factors play into the health and quality of the species of interest, but most questions revolve around what type of nutrients can be given with the lowest cost but provide the highest yield in growth of fishes or invertebrates. This goal is ubiquitous for any farming industry to create the fastest yield, however compromises come in the form of changing the diet can shift the quality and/or taste of the product (Calanche et al. 2019). In the past, fish meals (FM), mostly made from fish and not intended for direct human consumption, have been generated for carnivorous fishes, which contains a high source of protein, with essential amino acids and fats (Hardy, 2010). Also, this provides a dilemma, in which the 
availability of wild fish for the production of fish meal for any aquaculture species is limited, and the aquaculture production becomes a net consumer as opposed to a net producer (Hardy, 2010). In the past, there has been a focus on fish feed and fish oil as a source of nutrition for aquaculture. However, there has been a shift in giving the basic nutrients for aquaculture, in which "functional feeds" have been designed to improve the health and growth of a fish (Tacchi et al. 2011). Now additives included in feeds comprise of prebiotics, probiotics, immunostimulants, vitamins, nucleotides, minerals, plant and algal extracts. With these new strategies in shifting the diet of fishes, transcriptomic profiles can be used to understand how this may alter the physiological conditions of tissues within aquaculture species, and how this may benefit or be a detriment to the production of the species of interests, particularly in the gut.

The gastrointestinal tract offers so much insight on many functions such as digestion, osmoregulation, detoxification or immune function (Karasov and Douglas, 2013). Where many studies have monitored the gut of fishes when presenting some type of modification within their diet (Kaushik, 2002; Morais et al. 2012; Calduch-Giner et al. 2012; Lu et al. 2019). Many aquaculture species are carnivorous, such as the European seabass (Dicentrarchus labrax). This fish requires a vast amount of animal protein (43 - 50\% of its daily food intake) (Kaushik, 2002). In addition to proteins, carbohydrates, and lipid content within fish feed, the function feed is crucial in which it serves health benefits for the fish (Martin and Król, 2017). The function fish feed includes selenium, zinc and vitamins, and may contain other ingredients such as immunostimulants in which algal and plant extracts are integrated in these feeds. Also, prebiotics which usually stem from yeast extracts in order to stimulate the microbiome operating within the fish intestine (Hoseinifar et al., 2016). In all the modifications of diet within aquaculture, there is so much insight to be gained that can improve the quality of the aquaculture species of interest. 
Since FM and fish oil (FO) have been traditional marine resources as feed and a major source of dietary protein and lipids for aquaculture, recently, it has been a transition to include terrestrial plant products such as plant meals and vegetable oils (VO) into fish feed (Naylor et al. 2009; Hardy, 2010). This shift in diet for aquaculture purposes is critical to reduce the reliability of fish meal or wild caught fish used for fish feed which is a finite and ever more expensive resource (Naylor et al. 2009). With a majority of fish species which require a carnivorous diet and now with the increasing use of plant meal and VO in feed, questions arise on whether this shift to a plant protein-based diet have impacts on growth, immunity, and digestive physiology? Particularly, questions regarding absorption and digestion, the use of gut transcriptomics can elucidate a better understanding of metabolism and digestion. It is evident that the type of fish feed used in aquaculture impacts multiple aspects such as nutrition, development and health condition of the fish (Tacchi et al. 2011). Studies have shown that alternative plant-based ingredients, as opposed to marine derived products can have negative impacts on fish physiology such as growth, health, and disease resistance (Hardy, 2010). Nutrigenomics, a recent discipline that serves to improve many industries including aquaculture, has focused on the molecular movement and other dietary components required for aquaculture species (Vera et al 2017; Hakim et al. 2018). This field focuses on developing feed which has positive effects of economic value, the welfare of the fish, and supplying the market demands (Hakim et al. 2018). These studies involve altered diet conditions, and their effects are evaluated at the transcriptomic, proteomic, metabolomic, and epigenomic levels (Vera et al. 2017; Hakim et al. 2018). It is clear that the use of transcriptomics along with other fields of biology can provide profound answers to questions concerning aquaculture. In studies done in the rose spotted snapper (Lutjanus guttatus) when presented a vegetable based diet, recorded negative impacts where a vegetable diet did not provide 
all the required amino acid requirements for a developing fish (juvenile). Also, a decrease in gene expression of myogenic and other growth related genes was recorded (Escalante-Rojas et al. 2018). With the use of transcriptomic studies, it is clear that modifications to diets especially in the presence of a plant-based diet are necessary in order to understand how the species of interest responds to this altered diet at the molecular level. Ingredients such as soybean meal (SBM), soybean protein concentrate (SPC), corn gluten, sunflower meal and pea protein concentrate (PPC) are commonly used in fish feed (Vera et al. 2017). It has been shown that these plant ingredients contain secondary metabolites, which can be anti-nutritional factors (ANFs). These metabolites can reduce feed intake and the use of nutrients that's within vegetable-based feeds (Vera et al. 2017). When a plant-based diet is introduced, a shift from a marine diet containing fish meal $(80 \%)$ to a vegetable diet (10\% FM), has had an impact on the Atlantic salmon (Salmo salar), showing up-regulated genes involved in oxidative phosphorylation, pyruvate metabolism, tricarboxylic acid (TCA) cycle, glycolysis and fatty acid metabolism (Vera et al. 2017) as shown in the liver transcriptome. An additional factor that was considered in this study was ploidy (i.e. $2 n$ and $3 n$ ) which could be a potential factor that could influence how a diet shift may impact the development of these fishes. Therefore, different nutritional requirements have been shown for triploid salmon as compared to diploid salmon (Vera et al. 2017).

There have been extensive studies on the digestive physiology of fishes which has been applied to many facets of biology which includes applications to aquaculture (German et al. 2015, German et al. 2016, Wang et al. 2010, De Santis et al. 2015). A better understanding of the digestive enzymatic activity during a shift in diet can provide a better understanding of what type of activity is operating within the fishes of interest. There are many digestive enzymes which play a crucial role in digestion and leading to absorption, but these genes are crucial to the diet of the 
species of interest for aquaculture purposes. In addition, many aquaculture species represent a broad range of diets (i.e. carnivorous, omnivorous, or herbivorous) or even contain an ontogenetic diet shift through their life history (Chinook salmon; Duffy et al. 2010). A better understanding of enzymatic activity can provide a basic biological understanding of optimal enzymatic activity. There are two compelling hypotheses, the Adaptive Modulation Hypothesis (AMH; Karasov, 1992) which states a positive correlation between the digestive enzyme activities and the substrate that has been ingested that corresponds to those enzymes. This has been supported in many studies focused on carbohydrases from both herbivorous and omnivorous animals. In contrast, the Nutrient Balancing Hypothesis (NB; Clissold et al. 2010) supports the elevated expression levels of enzymes for a limiting dietary resource to ensure acquisition of these nutrients such as essential fatty acids. With the use of gut transcriptomics to better understand which genes are expressed associated with digestive enzymes can provide a better understanding about which genes are expressed to acquire certain nutrients. By understanding which proteolytic enzymes are necessary for digestion and absorption in the species of interest for aquaculture, efficient formulated feed can be developed for a specific species (Yasuike et al. 2018). A study done on Japanese amberjack (Seriola quinqueradiata) has highlighted the genes expressed in the gut which has shown expression of proteolytic digestive enzyme genes such as trypsinogen, two chymotrypsinogen gene, and a carboxypeptidase B gene within the intestine and rectum. Other digestive enzymes analyzed by Yasuike et al. (2018), showed three apolipoprotein genes, apolipo Eb, apolipo B-100, and apolipo A-1. Apolipoproteins are vital in lipid transport and uptake in vertebrates and has been shown to be synthesized primarily in the intestine and liver of most teleost. As a caveat, it has been suggested that the fish intestine transcriptomes are plastic, in which they can change spatially, seasonally, and with diet (Calduch-Giner et al. 2016). This provides a key detail of 
matching the available digestive enzymes present within the aquaculture species with the corresponding diet presented. Providing a general diet for multiple species which do not have the digestive enzymes to efficiently breakdown the feed can be counterproductive and detrimental to the health of the aquaculture species. Specialized feed or the possible use of CRISPR/Cas9 (gene editing) can be used to ensure optimal digestion and acquisition of nutrients, in which resources are not wasted and the health of the aquaculture species is not compromised. In addition, due to external fertilization and high fecundity in many aquaculture species serve as better candidates for gene editing as compared to terrestrial animals (Gratacap et al. 2019). More genomic and transcriptomic studies are being produced with species that naturally have an herbivorous diet such as the monkeyface prickleback fish (Cebidichthys violaceus; Heras et al. 2018). Although this is not a widely cultured fish, a better understanding of organisms that can digest and acquire nutrients from an herbivorous diet, can allows us to use gene editing tools in aquaculture species to ensure that genes that aide in the digestion of plant material obtain the proper nutrients and reduce the risk of ANF contribution which may have negative effects on the health of fishes.

\section{REPRODUCTION AND DEVELOPMENT}

In any form of culture or breeding, reproduction plays a crucial role in the large-scale commercial industries, in which some form of artificial reproduction is taking form. When dealing with species in the wild, species identification is crucial because the possibility of hybridization can occur. In addition, many marine species have wide distributions in which there can be putative population structure along their distribution. Depending on the species in aquaculture facilities, there are various forms of artificial reproduction, but to what extent does this impact the progeny and generations afterward with this form of artificial selection? Transcriptomic analyses can 
provide some insight on fitness of individuals and also an understanding of how reproduction at the molecular level operates within the species of interest.

An understanding of the genetic loci responsible in determination of sex in fishes can provide insight into reproduction, which is helpful for aquaculture and fisheries. Within fishes, sex determination is a dynamic process and has been observed in families or genera which can be modulated by external factors (Devlin and Nagahama, 2002). Sex determination can occur through monogenic or polygenic systems, which can be located on autosomes or sex chromosomes. With the use of transcriptomics, we can compare sexes to determine which loci contribute to sex determination (Chen et al. 2015; Sun et al. 2013; Lin et al. 2017). The transcriptome from reproductive tissue can also provide biological insight on understanding sex-related differences or sex differentiation in fishes (Zhang et al. 2019; Tao et al. 2018). Multiple candidate genes associated with sex determination, gametogenesis, and gonadal differentiation and maturation have been identified within fishes such as Dmy/dmrt1Yb, DM-W, DMRT1, Sox9, SDy, and Sox3 (Matsuda et al., 2002; Yokoi et al., 2002; Yano et al. 2012; Takehana et al., 2014). Amur sturgeon (Acipenser schrenckii), a species used for generating caviar, a transcriptomic study has shown how long noncoding RNAs (lncRNAs) might be one factor in regulating differential gene expression associated with sex-related differences (Zhang et al. 2019). More transcriptomic studies aimed at sex determination in fishes are still necessary in order to make broader inferences about reproduction which can be helpful for aquaculture management.

For both wild and domestic animals, egg production can be impacted by many factors, some that are highly variable, where the production of inviable eggs maybe common for a variety of species (Chapman et al. 2014). At early stages of vertebrate embryo development, there are rapid cell division processes occurring where in a synchronous fashion cells are dividing the zygote 
in a blastula. At this period, maternal RNA are essential, in which these gene transcripts were inherited in growing oocytes and direct embryogenesis (Chapman et al. 2014). In such studies have these transcripts encode regulators or participants in cell cycling (cyclins, nucleoplasmin), proliferation, growth and apoptosis (insulin-like growth factors and their receptor, prohibitin) and cytoskelton (tubulin beta, keratins 8 and 18; Aegerter et al. 2005; Bonnet et al. 2007a; Bonnet et al. 2007b). Farmed striped bass has had issues with egg quality (Chapman et al. 2014). It is clear that studies done on zebrafish and Japanese rice fish (medaka) can provide insights on reproduction and development (Vesterlund et al. 2011; Qiao et al. 2016), which can provide a better understanding of these fields and applied to aquaculture. For instance, the use of gene ontology (GO) annotations from D. rerio were used in a gene set enrichment analysis (GSEA) with head tissue from European glass eels to better understand the development of head shape dimorphisms (De Meyer et al. 2017). As more genomic and transcriptomic data becomes more readily available, we can make stronger inferences about fertilization, sex-determination, and reproductive physiology in fishes. This insight can be applied to making better decisions in spawning management.

\section{IMMUNE FUNCTION, STRESS, AND TOXICOLOGY}

An understanding of which genes are expressed in the presence of a pathogen, and also the diversity of genes related to immune function are important for aquaculture and fisheries. Multiple immune function genes are known to be under positive Darwinian selection, which is key especially for maintaining a healthy population within the confinement of a facility (Xiao et al. 2015). Multiple studies in vertebrates generally show that Major Histocompatibility genes are under positive Darwinian selection, in which they are part of the adaptive immune system (Xiao 
et al. 2015, Aguilar and Garza, 2005; Shad et al. 2012). Candidate tissues for transcriptomic studies would be head kidney, kidney, and spleen for understanding immune function (Chandhini and Kumar, 2018). Immune function does not operate in isolation, in which nutrition also plays a role in sustaining health of aquaculture species (Martin et al. 2010). Martin et al. (2010) showed that fasting of Atlantic Salmon (Salmo salar) decreased expression of immune function within the liver in the presence of a bacterial pathogen as compared to fishes that were fed and exposed to the pathogen. This suggests a mechanism for conservation of energy during starvation. Therefore, any alterations in feed can also have positive or negative impacts on immune function. If there are negative impacts on immune function, this provides stress on the organism which can result in a reduction of longevity.

Environmental stress can occur in multiple forms such as differences in temperature, salinity, $\mathrm{pH}$, spatial constraints, and pollutants. Exposure to different environmental conditions that provides some form of stress on the aquaculture species could hinder growth, development, and overall health of the fish. Several studies showed that stress exposure elicits a physiological and biochemical response within teleost fishes (Aluru and Vijayan, 2009). Of course, zebrafishes and medaka provide great models for understanding how pollutants can impact certain biological aspects, especially harmful consequences have been reported in development, endocrine and reproductive aspects (Weber et al. 2013). A better understanding of the immune function and exposure to specific pollutants or stressors can have an extensive impact of growth, reproduction and longevity. The use of transcriptomics hold strong promise in extending the lives of individuals within aquaculture and also can be litmus test for ensuring the health of these species which is important for sustaining aquaculture optimal for human consumption as well. 


\section{ADAPTATIONS, MOLECULAR EVOLUTION, AND POPULATION GENETICS}

It is clear that physiological adaptations are crucial for organisms to survive within their habitats, especially if human activities have altered these conditions, due to aquapens for mass production or as a consequence of climate change impacting the temperature of our oceans. Many species of economic value can also serve with great interests to applications in evolution. Multiple studies have used comparative transcriptomics to identify orthologous gene pairs/clusters and then estimate natural selection by using a form of estimating non-synonymous and synonymous rates (omega), where an omega value $>1$ indicates a positive selection, a value $=1$ means a neutral selection, and a value $<1$ is purifying selection (Heras et al. 2011, Heras et al. 2015 and Heras and Aguilar, 2019; Tong et al. 2015; Xiao et al. 2015). Many of these genes can provide us with a better understanding if there are general patterns of selection operating on certain genes especially if multiple species are exposed to similar habitats (e.g. temperature, $\mathrm{pH}$, oceanic depth, differences in salinity). It is clear that some genes under positive Darwinian selection contribute to a physiological adaptation in a given environment. Marine rockfishes (genus Sebastes) serves this unique opportunity to understand evolution of a genus that composed of 105 (Love et al. 2002) species but also important applied to our understanding to aquaculture purposes. Rockfishes are clear examples of adaptive radiations within marine habitats and they are a cluster of multiple species which can live greater than 100 years. As part of Heras et al. 2011, Heras et al. 2015 and Heras and Aguilar, 2019, we see multiple candidate genes under positive Darwinian selection. These estimates of positive Darwinian selection provide some insight on adaptation at the molecular level and elucidate patterns within this speciose group. There have been several 
candidate genes of interests which involve genes associated with metabolism, longevity, reproduction, and oxygen consumption. It was shown in Heras and Aguilar 2019 that hemoglobin subunit alpha is under strong positive Darwinian selection within rockfishes through a comparative transcriptomic analysis. In addition, understanding how well a species responds to novel environmental conditions such as changes in $\mathrm{pCO}_{2}$ which is likely in the occurrence of climate change within our oceans. A study done by Hamilton et al. (2017) with rockfishes has demonstrated what the transcriptomic profile would look like in the presence of elevated $p \mathrm{CO}_{2}$, a simulated environment due to anticipated climate change. Studies like these are of interests because not only do we understand the evolutionary adaptation of the species in interests but also what does this mean for conservation and fisheries efforts.

The fish specific genome duplication (FSGD) has been estimated to have occurred around 350 million years ago (Meyer and Van de Peer, 2005). With a duplicated genome, this provides the opportunity for novel gene functions to occur via neofunctionalization or subfunctionalization (Wolfe, 2001). With novel functions, these duplicated genes can also be favorable and can become fixed within a population as a result of positive selection. There are about $\sim 25,000$ different species of teleost fishes presently known, which is more than any other vertebrate group (Meyer and Van de Peer, 2005). Therefore, with the presence of gene duplications, there is the opportunity for expression profiles to be different from what is seen in other vertebrates. Although there are many facets that contribute to adaptation and speciation, some of the basic understanding of the evolutionary patterns within organisms can be assessed with access to genomic information such as the identification of positive selection within the transcriptome and the identification of orthologous and paralogous genes. In addition, by understanding which loci are expressed or if 
there are multiple paralogous genes expressed, this can provide insight on using gene editing methods to make sure that similar copies are used for a desired phenotype in the species of interest. Population genetics or genomic studies have always played a strong role in understanding population structure of a variety of aquaculture species such as salmon, trout, rockfishes, and etc. Although most population genetic studies focus on using genomic sequencing information to detect SNPs, this information gives us a better understanding about population structure or identifying candidate loci responsible for local adaptative traits (Nielsen et al. 2009). Transcriptomic information can be used to make these inferences about divergence in populations, which has been conducted between dwarf and normal whitefish to identify SNP markers within coding regions (Renaut and Bernatchez, 2011). With more loci to analyze, population genomic analyses can give a better understanding about the evolutionary processes within or between fishes that are in captivity (reared) or in the wild.

\section{MICROBIOME AND APPLICATIONS FOR CONSERVATION AND AQUACULTURE MANAGEMENT}

When thinking about the biology of a given aquaculture species and if an immense amount of transcriptomic data was available for such species, there is still more biological information that can be insightful since that organism does not operate in isolation. Bacterial taxa are commonly viewed as pathogens, but many bacterial taxa have mutualistic relationships with fish that translate as health of a fish. With a systems biology approach, which already exists in the form of a Holo-Omic effort to represent a broad understanding of the biology of a species of interest, which includes the microbiome (Limborg et al. 2018). With the current technology and advancement in our understanding of microbial genomes, pairing the transcriptome of bacteria residing within the fish of interest and aids in digestion or other physiological functions, 
will provide greater insight on genomic and transcriptomic studies. This approach offer many opportunities to better understand co-evolutionary processes that operate between the gut microbiome and the host (Mekuchi et al. 2019). In addition, metatranscriptomics (transcriptomes of microbiota) serves as a useful tool for understanding how genes within the microbe aid in digestion (Wu et al. 2015).

The use of transcriptomics, a subset of genes expressed within the genome, is a powerful resource for rapidly identifying coding genes and non-coding transcripts from the genome as opposed to sequencing the genome with no prior knowledge. Further, many studies contributed to advance in knowledge of the constituents of a genome which can provide understanding on loci that are associated with risk factors for genetic disorders, variation in immune function, specialization (i.e. dietary tolerances), and reproduction (Ryder, 2005). These factors may provide insightful information not only for evolutionary biology but for aquaculture, fisheries, and conservation management as well. We can use transcriptomics to advance our understanding of a commercially important fishes and reveal how biological processes are operating at the transcriptomic level. Many species are overfished, and some have been listed either as threatened or as endangered species (Magnuson-Ford et al. 2009). The advancement in transcriptomic studies can elucidate our understanding of risk factors for genetic disorders, variation in immune function, specialization (i.e. dietary tolerances), and reproduction. These can enhance our knowledge about physiology and to propose an effective guide for conservation management by means of improving wildlife health conditions and plans for intervention of population viability (Ryder, 2005). With recent advancements in genetic sequencing technology and computational capabilities, we can further advance the field of aquaculture for the health of the species consumed and in turn will benefit us. 
Table 1. Contemporary papers on aquaculture transcriptomics (past three years)

\begin{tabular}{|c|c|c|c|c|}
\hline Study Focus & Species & $\begin{array}{l}\text { Common } \\
\text { Name }\end{array}$ & Tissue Type(s) & Reference \\
\hline Adaptive evolution & $\begin{array}{l}\text { Sebastes carnatus, S. nebulosus, } \\
\text { S. maliger, S. mystinus, and S. } \\
\text { serranoides }\end{array}$ & $\begin{array}{l}\text { Gopher, } \\
\text { China, } \\
\text { quillback, } \\
\text { blue, and } \\
\text { olive } \\
\text { rockfishes }\end{array}$ & brain & Heras and Aguilar, 2019 \\
\hline $\begin{array}{l}\text { Climate change } \\
\text { elevated pCO2 }\end{array}$ & Sebastes carnatus and S. mystinus & $\begin{array}{l}\text { Gopher } \\
\text { and Blue } \\
\text { rockfishes }\end{array}$ & white muscle & Hamilton et al. 2017 \\
\hline $\begin{array}{l}\text { Climate change } \\
\text { stress }\end{array}$ & Sebastes mystinus & $\begin{array}{l}\text { Blue } \\
\text { rockfish }\end{array}$ & $\begin{array}{l}\text { white muscle, gill, and } \\
\text { liver }\end{array}$ & Cline et al. 2020 \\
\hline Diet & Dicentrarchus labrax & $\begin{array}{l}\text { European } \\
\text { seabass }\end{array}$ & proximal intestines & Leduc et al. 2018 \\
\hline $\begin{array}{l}\text { Diet and immune } \\
\text { response }\end{array}$ & Epinephelus akaara & $\begin{array}{l}\text { Hong } \\
\text { Kong } \\
\text { grouper }\end{array}$ & liver & Yang et al. 2018 \\
\hline Diet replacement & Salmo salar $L$. & $\begin{array}{l}\text { Atlantic } \\
\text { salmon }\end{array}$ & liver, midgut and hindgut & Betancor et al. 2017 \\
\hline Egg quality & Dicentrarchus labrax & sea bass & fertilized eggs & Żarski et al. 2017 \\
\hline $\begin{array}{l}\text { Fishmeal based } \\
\text { diet }\end{array}$ & Carassius gibelio & gibel carp & liver & Xu et al. 2019 \\
\hline $\begin{array}{l}\text { Genome and } \\
\text { transcriptome } \\
\text { characterization of } \\
\text { the digestive tract }\end{array}$ & Seriola quinqueradiata & $\begin{array}{l}\text { Japanese } \\
\text { amberjack } \\
\text { (yellowtail) }\end{array}$ & $\begin{array}{l}\text { gills, skin, fins, red muscle, } \\
\text { white muscle, heart, kid- } \\
\text { ney, spleen, stomach, } \\
\text { intestine, pyloric caeca, } \\
\text { liver, gallbladder, retina, } \\
\text { cerebellum, optic lobe, } \\
\text { olfactory lobe and ovary }\end{array}$ & Yasuike et al. 2018 \\
\hline Growth/atrophy & Lutjanus guttatus & $\begin{array}{l}\text { rose } \\
\text { spotted } \\
\text { snapper }\end{array}$ & $\begin{array}{l}\text { spleen, gills, brain, heart, } \\
\text { testis, liver, gut, muscle, } \\
\text { dark skin, white skin and } \\
\text { visceral fat }\end{array}$ & Escalante-Rojas et al. 2018 \\
\hline $\begin{array}{l}\text { Head shape } \\
\text { dimorphism/growth } \\
\text { rate and } \\
\text { chemotaxis }\end{array}$ & Anguilla anguilla & $\begin{array}{l}\text { European } \\
\text { glass eel }\end{array}$ & head & Meyer et al. 2017 \\
\hline $\begin{array}{l}\text { Nutrition (plant } \\
\text { based feed) }\end{array}$ & Salmo salar & $\begin{array}{l}\text { Atlantic } \\
\text { salmon }\end{array}$ & liver & Vera et al. 2017 \\
\hline $\begin{array}{l}\text { Sex related } \\
\text { differences }\end{array}$ & Acipenser schrenckii & $\begin{array}{l}\text { Amur } \\
\text { sturgeon }\end{array}$ & testes, ovaries, and livers & Zhang et al. 2019 \\
\hline $\begin{array}{l}\text { Sex related/sex } \\
\text { determination }\end{array}$ & Oreochromis niloticus & Nile tilapia & gonads & Tao et al. 2018 \\
\hline $\begin{array}{l}\text { Sex related/sex } \\
\text { determination }\end{array}$ & Symphysodon haraldi & Discus fish & gonads & Lin et al. 2017 \\
\hline
\end{tabular}




\begin{tabular}{|l|l|l|l|l|}
\hline $\begin{array}{l}\text { Sex reversal/ } \\
\text { temperature }\end{array}$ & Oreochromis niloticus & Nile tilapia & gonads & Wang et al. 2019 \\
\hline $\begin{array}{l}\text { Stress Response } \\
\text { and aggression }\end{array}$ & Oreochromis niloticus & Nile tilapia & hypothalamus & Rodriguez-Barreto et al. 2019 \\
\hline
\end{tabular}




\section{REFERENCES}

Aegerter, S., Jalabert, B., \& Bobe, J. (2005). Large scale real-time PCR analysis of mRNA abundance in rainbow trout eggs in relationship with egg quality and post-ovulatory ageing. Molecular Reproduction and Development: Incorporating Gamete Research, 72(3), 377-385.

Aguilar, A., \& Garza, J. C. (2005). Analysis of major histocompatibility complex class II Beta genes from rockfishes (genus Sebastes). Journal of fish biology, 67(4), 1021-1028.

Aluru, N., \& Vijayan, M. M. (2009). Stress transcriptomics in fish: a role for genomic cortisol signaling. General and comparative endocrinology, 164(2-3), 142-150.

Barange, M., Bahri, T., Beveridge, M. C., Cochrane, K. L., Funge-Smith, S., \& Poulain, F. (2018). Impacts of climate change on fisheries and aquaculture. Synthesis of current knowledge, adaptation and mitigation options. Rome: Food and Agriculture Organization of the United Nations.

Benestan L. (2019) Population Genomics Applied to Fishery Management and Conservation. In: Oleksiak M., Rajora O. (eds) Population Genomics: Marine Organisms. Population Genomics. Springer, Cham

Betancor, M. B., Li, K., Sprague, M., Bardal, T., Sayanova, O., Usher, S., ... \& Tocher, D. R. (2017). An oil containing EPA and DHA from transgenic Camelina sativa to replace marine fish oil in feeds for Atlantic salmon (Salmo salar L.): Effects on intestinal transcriptome, histology, tissue fatty acid profiles and plasma biochemistry. PloS one, 12(4), e0175415.

Bonnet, E., Fostier, A., \& Bobe, J. (2007). Microarray-based analysis of fish egg quality after natural or controlled ovulation. Bmc Genomics, 8(1), 55.

Bonnet, E., Montfort, J., Esquerre, D., Hugot, K., Fostier, A., \& Bobe, J. (2007). Effect of photoperiod manipulation on rainbow trout (Oncorhynchus mykiss) egg quality: A genomic study. Aquaculture, 268(1-4), 13-22.

Calanche, J. B., Beltrán, J. A., \& Hernández Arias, A. J. (2019). Aquaculture and sensometrics: the need to evaluate sensory attributes and the consumers' preferences. Reviews in Aquaculture.

Calduch-Giner, J. A., Sitjà-Bobadilla, A., \& Pérez-Sánchez, J. (2016). Gene expression profiling reveals functional specialization along the intestinal tract of a carnivorous teleostean fish (Dicentrarchus labrax). Frontiers in physiology, 7, 359.

Chapman, R. W., Reading, B. J., \& Sullivan, C. V. (2014). Ovary transcriptome profiling via artificial intelligence reveals a transcriptomic fingerprint predicting egg quality in striped bass, Morone saxatilis. PLoS One, 9(5), e96818. 
Chandhini, S., \& Rejish Kumar, V. J. (2019). Transcriptomics in aquaculture: current status and applications. Reviews in Aquaculture, 11(4), 1379-1397.

Chen, X., Mei, J., Wu, J., Jing, J., Ma, W., Zhang, J., ... \& Gui, J. F. (2015). A comprehensive transcriptome provides candidate genes for sex determination/differentiation and SSR/SNP markers in yellow catfish. Marine Biotechnology, 17(2), 190-198.

Cline, A. J., Hamilton, S. L., \& Logan, C. A. (2020). Effects of multiple climate change stressors on gene expression in blue rockfish (Sebastes mystinus). Comparative Biochemistry and Physiology Part A: Molecular \& Integrative Physiology, 239, 110580.

Clissold, F. J., Tedder, B. J., Conigrave, A. D., \& Simpson, S. J. (2010). The gastrointestinal tract as a nutrient-balancing organ. Proceedings of the Royal Society B: Biological Sciences, 277(1688), 1751-1759.

Dahm, R., \& Geisler, R. (2006). Learning from small fry: the zebrafish as a genetic model organism for aquaculture fish species. Marine biotechnology, 8(4), 329-345.

De Meyer, J., Maes, G. E., Dirks, R. P., \& Adriaens, D. (2017). Differential gene expression in narrow-and broad-headed European glass eels (Anguilla anguilla) points to a transcriptomic link of head shape dimorphism with growth rate and chemotaxis. Molecular ecology, 26(15), 39433953.

De Santis, C., Bartie, K. L., Olsen, R. E., Taggart, J. B., \& Tocher, D. R. (2015). Nutrigenomic profiling of transcriptional processes affected in liver and distal intestine in response to a soybean meal-induced nutritional stress in Atlantic salmon (Salmo salar). Comparative Biochemistry and Physiology Part D: Genomics and Proteomics, 15, 1-11.

Devlin, R. H., \& Nagahama, Y. (2002). Sex determination and sex differentiation in fish: an overview of genetic, physiological, and environmental influences. Aquaculture, 208(3-4), 191364.

Dunham, R. (2019) Genetics, Lucas, John S., Paul C. Southgate, and Craig S. Tucker, eds. Aquaculture: Farming aquatic animals and plants. Wiley-Blackwell.

Escalante-Rojas, M., Peña, E., Hernández, C., Llera-Herrera, R., \& Garcia-Gasca, A. (2018). De novo transcriptome assembly for the rose spotted snapper Lutjanus guttatus and expression analysis of growth/atrophy-related genes. Aquaculture research, 49(4), 1709-1722.

Garber, A. F., \& Sullivan, C. V. (2006). Selective breeding for the hybrid striped bass (Morone chrysops, Rafinesquex M. saxatilis, Walbaum) industry: status and perspectives. Aquaculture Research, 37(4), 319-338.

Gjedrem, T., \& Robinson, N. (2014). Advances by selective breeding for aquatic species: a review. Agricultural Sciences, 5(12), 1152. 
Gjedrem, T., Robinson, N., \& Rye, M. (2012). The importance of selective breeding in aquaculture to meet future demands for animal protein: a review. Aquaculture, 350, 117-129.

Gratacap, R. L., Wargelius, A., Edvardsen, R. B., \& Houston, R. D. (2019). Potential of genome editing to improve aquaculture breeding and production. Trends in Genetics. 35(9), 672-684.

Hakim, M. M., Ganai, N. A., Ahmad, S. M., Asmi, O., Akram, T., Hussain, S., ... \& Gora, A. H. (2018). Nutrigenomics: Omics approach in aquaculture research to mitigate the deficits in conventional nutritional practices. 6(4): 582-587.

Hamilton, S. L., Logan, C. A., Fennie, H. W., Sogard, S. M., Barry, J. P., Makukhov, A. D., ... \& Bernardi, G. (2017). Species-specific responses of juvenile rockfish to elevated pCO2: from behavior to genomics. PloS one, 12(1), e0169670.

Hardy, R. W. (2010). Utilization of plant proteins in fish diets: effects of global demand and supplies of fishmeal. Aquaculture Research, 41(5), 770-776.

Heras, J., Chakraborty, M., Emerson, J. J., \& German, D. (2018). Physiological genomics of dietary adaptation in a marine herbivorous fish. bioRxiv, 457705.

Heras, J., and Aguilar, A. (2019). Comparative transcriptomics reveals patterns of adaptive evolution associated with depth and age within marine rockfishes (Sebastes). Journal of Heredity. 110(3): 340-350.

Heras, J., Koop, B. F., and Aguilar, A. 2011. A transcriptomic scan for positively selected genes in two closely related marine fishes: Sebastes caurinus and S. rastrelliger. Marine Genomics, 4(2), 93-98.

Heras, J., McClintock, K., Sunagawa, S., and Aguilar, A. (2015). Gonadal transcriptomics elucidate patterns of adaptive evolution within marine rockfishes (Sebastes). BMC Genomics, 16, 656.

Horgan, R. P., \& Kenny, L. C. (2011). 'Omic'technologies: genomics, transcriptomics, proteomics and metabolomics. The Obstetrician \& Gynaecologist, 13(3), 189-195.

Hoseinifar, S. H., Ring $\varnothing$, E., Shenavar Masouleh, A., \& Esteban, M. Á. (2016). Probiotic, prebiotic and synbiotic supplements in sturgeon aquaculture: a review. Reviews in Aquaculture, 8(1), 89-102.

Karasov, W. H. (1992). Tests of the adaptive modulation hypothesis for dietary control of intestinal nutrient transport. American Journal of Physiology-Regulatory, Integrative and Comparative Physiology, 263(3), R496-R502.

Karasov, W., \& Douglas, A. E. (2013). Comparative digestive physiology. Comprehensive Physiology, 3(2), 741-783. 
Kaushik SJ. European sea bass, Dicentrarchus labrax. Nutrient requirements and feeding of finfish for aquaculture, CABI publishing, 28-39.

Krogdahl, Å., Gajardo, K., Kortner, T. M., Penn, M., Gu, M., Berge, G. M., \& Bakke, A. M. (2015). Soya saponins induce enteritis in Atlantic salmon (Salmo salar L.). Journal of agricultural and food chemistry, 63(15), 3887-3902.

Leduc, A., Zatylny-Gaudin, C., Robert, M., Corre, E., Le Corguille, G., Castel, H., ... \& Henry, J. (2018). Dietary aquaculture by-product hydrolysates: impact on the transcriptomic response of the intestinal mucosa of European seabass (Dicentrarchus labrax) fed low fish meal diets. BMC genomics, 19(1), 396.

Liao, X., Cheng, L., Xu, P., Lu, G., Wachholtz, M., Sun, X., \& Chen, S. (2013). Transcriptome analysis of crucian carp (Carassius auratus), an important aquaculture and hypoxia-tolerant species. PloS one, 8(4), e62308.

Limborg, M. T., Alberdi, A., Kodama, M., Roggenbuck, M., Kristiansen, K., \& Gilbert, M. T. P. (2018). Applied hologenomics: Feasibility and potential in aquaculture. Trends in biotechnology, 36(3), 252-264.

Lin, R., Wang, L., Zhao, Y., Gao, J., \& Chen, Z. (2017). Gonad transcriptome of discus fish (Symphysodon haraldi) and discovery of sex-related genes. Aquaculture Research, 48(12), 59936000 .

Lubzens, E., Bobe, J., Young, G., \& Sullivan, C. V. (2017). Maternal investment in fish oocytes and eggs: the molecular cargo and its contributions to fertility and early development. Aquaculture, 472, 107-143.

Lucas, J. S., Southgate, P. C., \& Tucker, C. S. (Eds.). (2019). Aquaculture: Farming aquatic animals and plants. Wiley-Blackwell. Pg. 127.

Martin, S. A., Douglas, A., Houlihan, D. F., \& Secombes, C. J. (2010). Starvation alters the liver transcriptome of the innate immune response in Atlantic salmon (Salmo salar). BMC genomics, 11(1), 418.

Martin, S. A., \& Król, E. (2017). Nutrigenomics and immune function in fish: new insights from omics technologies. Developmental \& Comparative Immunology, 75, 86-98.

Martínez, H., Barrachina, S., Castillo, M., Tárraga, J., Medina, I., Dopazo, J., \& Quintana-Ortí, E. S. (2018). A framework for genomic sequencing on clusters of multicore and manycore processors. The International Journal of High Performance Computing Applications, 32(3), 393406.

Matsuda, M., Nagahama, Y., Shinomiya, A., Sato, T., Matsuda, C., Kobayashi, T., ... \& Hori, H. (2002). DMY is a Y-specific DM-domain gene required for male development in the medaka fish. Nature, 417(6888), 559-563. 
Mazurais, D., Darias, M., Zambonino-Infante, J. L., \& Cahu, C. L. (2011). Transcriptomics for understanding marine fish larval development. Canadian Journal of Zoology, 89(7), 599-611.

Meyer, A., \& Van de Peer, Y. (2005). From 2R to 3R: evidence for a fish-specific genome duplication (FSGD). Bioessays, 27(9), 937-945.

Mekuchi, M., Asakura, T., \& Kikuchi, J. (2019). New Aquaculture Technology Based on HostSymbiotic Co-metabolism. In Marine Metagenomics (pp. 189-228). Springer, Singapore.

Meyer, A., \& Van de Peer, Y. (2005). From 2R to 3R: evidence for a fish-specific genome duplication (FSGD). Bioessays, 27(9), 937-945.

Morais, S., Silva, T., Cordeiro, O., Rodrigues, P., Guy, D. R., Bron, J. E., ... \& Tocher, D. R. (2012). Effects of genotype and dietary fish oil replacement with vegetable oil on the intestinal transcriptome and proteome of Atlantic salmon (Salmo salar). BMC Genomics, 13(1), 448.

Naylor, R. L., Hardy, R. W., Bureau, D. P., Chiu, A., Elliott, M., Farrell, A. P., ... \& Nichols, P. D. (2009). Feeding aquaculture in an era of finite resources. Proceedings of the National Academy of Sciences, 106(36), 15103-15110.

Nielsen, E. E., Hemmer-Hansen, J. A. K. O. B., Larsen, P. F., \& Bekkevold, D. (2009). Population genomics of marine fishes: identifying adaptive variation in space and time. Molecular ecology, 18(15), 3128-3150.

Pujolar, J. M., Marino, I. A., Milan, M., Coppe, A., Maes, G. E., Capoccioni, F., ... \& Cramb, G. (2012). Surviving in a toxic world: transcriptomics and gene expression profiling in response to environmental pollution in the critically endangered European eel. BMC genomics, 13(1), 507.

Qian, X., Ba, Y., Zhuang, Q., \& Zhong, G. (2014). RNA-Seq technology and its application in fish transcriptomics. Omics: a journal of integrative biology, 18(2), 98-110.

Qiao, Q., Le Manach, S., Huet, H., Duvernois-Berthet, E., Chaouch, S., Duval, C., ... \& Lennon, S. (2016). An integrated omic analysis of hepatic alteration in medaka fish chronically exposed to cyanotoxins with possible mechanisms of reproductive toxicity. Environmental pollution, 219, 119-131.

Rodriguez-Barreto, D., Rey, O., Uren-Webster, T. M., Castaldo, G., Consuegra, S., \& Garcia de Leaniz, C. (2019). Transcriptomic response to aquaculture intensification in Nile tilapia. Evolutionary applications, 12(9), 1757-1771.

Schadt, E. E., Linderman, M. D., Sorenson, J., Lee, L., \& Nolan, G. P. (2010). Computational solutions to large-scale data management and analysis. Nature reviews genetics, 11(9), 647. 
Schad, J., Voigt, C. C., Greiner, S., Dechmann, D. K., \& Sommer, S. (2012). Independent evolution of functional MHC class II DRB genes in New World bat species. Immunogenetics, 64(7), 535-547.

Sun, F., Liu, S., Gao, X., Jiang, Y., Perera, D., Wang, X., ... \& Dunham, R. (2013). Male-biased genes in catfish as revealed by RNA-Seq analysis of the testis transcriptome. PloS one, 8(7), e68452.

Tao, W., Chen, J., Tan, D., Yang, J., Sun, L., Wei, J., ... \& Wang, D. (2018). Transcriptome display during tilapia sex determination and differentiation as revealed by RNA-Seq analysis. BMC genomics, 19(1), 363.

Tacchi, L., Bickerdike, R., Douglas, A., Secombes, C. J., \& Martin, S. A. (2011). Transcriptomic responses to functional feeds in Atlantic salmon (Salmo salar). Fish \& shellfish immunology, 31(5), 704-715.

Takehana, Y., Matsuda, M., Myosho, T., Suster, M. L., Kawakami, K., Shin, T., ... \& Hamaguchi, S. (2014). Co-option of Sox 3 as the male-determining factor on the Y chromosome in the fish Oryzias dancena. Nature communications, 5(1), 1-10.

Tong, C., Zhang, C., Zhang, R., \& Zhao, K. (2015). Transcriptome profiling analysis of naked carp (Gymnocypris przewalskii) provides insights into the immune-related genes in highland fish. Fish \& shellfish immunology, 46(2), 366-377.

Ulloa, P. E., Medrano, J. F., \& Feijoo, C. G. (2014). Zebrafish as animal model for aquaculture nutrition research. Frontiers in genetics, 5, 313.

Vesterlund, L., Jiao, H., Unneberg, P., Hovatta, O., \& Kere, J. (2011). The zebrafish transcriptome during early development. BMC developmental biology, 11(1), 30.

Vera, L. M., Metochis, C., Taylor, J. F., Clarkson, M., Skjaerven, K. H., Migaud, H., \& Tocher, D. R. (2017). Early nutritional programming affects liver transcriptome in diploid and triploid Atlantic salmon, Salmo salar. BMC genomics, 18(1), 886.

Wadapurkar, R. M., \& Vyas, R. (2018). Computational analysis of next generation sequencing data and its applications in clinical oncology. Informatics in Medicine Unlocked, 11, 75-82.

Wang, Z., Du, J., Lam, S. H., Mathavan, S., Matsudaira, P., \& Gong, Z. (2010). Morphological and molecular evidence for functional organization along the rostrocaudal axis of the adult zebrafish intestine. BMC Genomics, 11(1), 392.

Wang, Z., Gerstein, M., \& Snyder, M. (2009). RNA-Seq: a revolutionary tool for transcriptomics. Nature reviews genetics, 10(1), 57. 
Wang, J., Liu, Y., Jiang, S., Li, W., Gui, L., Zhou, T., ... \& Chen, L. (2019). Transcriptomic and epigenomic alterations of Nile tilapia gonads sexually reversed by high temperature. Aquaculture, 508, 167-177.

Weber, G. J., Sepúlveda, M. S., Peterson, S. M., Lewis, S. S., \& Freeman, J. L. (2013). Transcriptome alterations following developmental atrazine exposure in zebrafish are associated with disruption of neuroendocrine and reproductive system function, cell cycle, and carcinogenesis. Toxicological sciences, 132(2), 458-466.

Wolfe KH. (2001). Yesterday's polyploids and the mystery of diploidization. Nat Rev Genet. 2(5): 333-341.

World Bank. (2013). Fish to 2030: Prospects for fisheries and aquaculture. In Agriculture and Environmental Services Discussion Paper, 3.

Wu, N., Song, Y. L., Wang, B., Zhang, X. Y., Zhang, X. J., Wang, Y. L., ... \& Zhang, Y. A. (2016). Fish gut-liver immunity during homeostasis or inflammation revealed by integrative transcriptome and proteome studies. Scientific reports, 6, 36048.

Wu, S., Ren, Y., Peng, C., Hao, Y., Xiong, F., Wang, G., ... \& Angert, E. R. (2015).

Metatranscriptomic discovery of plant biomass-degrading capacity from grass carp intestinal microbiomes. FEMS microbiology ecology, 91(10), fiv107.

Xiao, J., Zhong, H., Liu, Z., Yu, F., Luo, Y., Gan, X., \& Zhou, Y. (2015). Transcriptome analysis revealed positive selection of immune-related genes in tilapia. Fish \& shellfish immunology, 44(1), 60-65.

Xu, W., Jin, J., Han, D., Liu, H., Zhu, X., Yang, Y., \& Xie, S. (2019). Physiological and transcriptomic responses to fishmeal-based diet and rapeseed meal-based diet in two strains of gibel carp (Carassius gibelio). Fish physiology and biochemistry, 45(1), 267-286.

Yang, Y., Han, T., Xiao, J., Li, X., \& Wang, J. (2018). Transcriptome analysis reveals carbohydrate-mediated liver immune responses in Epinephelus akaara. Scientific reports, 8(1), 639.

Yano, A., Guyomard, R., Nicol, B., Jouanno, E., Quillet, E., Klopp, C., ... \& Guiguen, Y. (2012). An immune-related gene evolved into the master sex-determining gene in rainbow trout, Oncorhynchus mykiss. Current Biology, 22(15), 1423-1428.

Yasuike, M., Iwasaki, Y., Nishiki, I., Nakamura, Y., Matsuura, A., Yoshida, K., ... \& Fujiwara, A. (2018). The yellowtail (Seriola quinqueradiata) genome and transcriptome atlas of the digestive tract. DNA Research, 25(5), 547-560.

Yokoi, H., Kobayashi, T., Tanaka, M., Nagahama, Y., Wakamatsu, Y., Takeda, H., ... \& Ozato, K. (2002). Sox9 in a teleost fish, medaka (Oryzias latipes): evidence for diversified function of 
Sox9 in gonad differentiation. Molecular Reproduction and Development: Incorporating Gamete Research, 63(1), 5-16.

Żarski, D., Nguyen, T., Le Cam, A., Montfort, J., Dutto, G., Vidal, M. O., ... \& Bobe, J. (2017). Transcriptomic profiling of egg quality in sea bass (Dicentrarchus labrax) sheds light on genes involved in ubiquitination and translation. Marine biotechnology, 19(1), 102-115.

Zhang, X., Shi, J., Sun, Y., Zhu, Y., Zhang, Z., \& Wang, Y. (2019). Transcriptome analysis provides insights into differentially expressed genes and long noncoding RNAs involved in sexrelated differences in Amur sturgeon (Acipenser schrenckii). Molecular reproduction and development, 86(2), 132-144. 